\title{
An Integrated Rehabilitation Model: An Ideal Framework for Limiting Health Care Costs
}

\author{
Luca Collebrusco \\ Rehabilitation Unit, National Health Service of Umbria, Perugia, Italy \\ Email: tdr.colle@tiscali.it
}

Received 3 January 2015; accepted 14 January 2015; published 15 January 2015

Copyright (C 2015 by author and Scientific Research Publishing Inc.

This work is licensed under the Creative Commons Attribution International License (CC BY).

http://creativecommons.org/licenses/by/4.0/

c) (†) Open Access

\begin{abstract}
The financial crisis has caused a severe limitation of resources for the public health service and rehabilitation. The proposal of integrated diagnosis and treatment in rehabilitation, involving the introduction of new therapeutic models alongside orthodox models, could lead to a reduction in health care costs through better patient compliance. In rehabilitative assistance in health care, the limiting of financial resources can be simplified, given its multifaceted nature and the need to integrate clinical experience with research. In addition, the phases of rehabilitative recovery do not focus on organ damage, but improved participation and the reduction of disability. For this reason, we have considered incorporating narrative based medicine (NBM) and Psycho-Neuro-ImmunoEndocrinology (PNEI) in the rehabilitation process through an empathetic approach, taking evidence based medicine (EBM) into account, thus creating a "framework" of reference. Managing patients through this "framework" would be a move towards an integrated model of care that could lead to a reduction in health care costs, given the aging population and the rise in patients with chronic pain. The decision to modify health care in rehabilitative assistance through a new "framework" will require time, organizational capacity and experimentation, but may represent the appropriate response for an improved quality of life for patients and a better allocation of resources.
\end{abstract}

\section{Keywords}

Rehabilitation, Integrated Therapeutic Model, Health Care Costs

\section{Introduction}

In the light of the recent financial crisis, which has resulted in economic policies that severely limit the public health service, an integrated approach to rehabilitation can be proposed, which combines standard methods of diagnosis and treatment with the most up to date therapy and assistance models. 
According to work carried out at the international level, incorporating other therapeutic models alongside orthodox methods of diagnosis and therapy would not require new funding. On the contrary, it could lead to cost reductions, as a result of increased patient compliance [1]. This can also prove productive in rehabilitation, given that there is no universally accepted definition or theoretical model of reference.

Rehabilitation includes a variety of measures which are physical, functional, psychological and psycho-social. It is precise, because of this multi-faceted nature, that a form of rehabilitation may exist that can be conceived of as a combination of a variety of clinical, treatment and care models, which can be integrated with each other, creating a "framework" of reference for the evaluation of, and activities involving, the patient.

In recent years, rehabilitation has seen a gradual advancement in research, in both purely technical terms and in terms of knowledge. More than 10,000 randomized clinical trials have been held, and the quality of the proposed studies is progressively developing [2] [3]. Therapeutic decisions are being made based on the results available in the literature and Evidence-Based Rehabilitation (EBR), which summarizes the basic concepts of Evidence-Based Medicine (EBM) and Evidence-Based Practice (EBP), and now represents the model for integrating clinical experience and the knowledge/application of the most validated techniques in the literature [4].

It is precisely this integration between clinical experience and knowledge that was officially confirmed in 2005, when, with the "Sicily Statement on Evidence-based Practice", an international research team affirmed that health professionals should possess a critical spirit both in relation to their professional practice and scientific evidence, be able to research, evaluate and apply the best evidence, and be willing to implement guidelines and care approaches. The absence of these qualities will make it impossible for healthcare organizations to provide "the best care, based on evidence" [5].

It should be pointed out that research in the field of rehabilitation presents some particularities that distinguish it from other disciplines. The outcomes of rehabilitation, for example, are difficult to measure, as they aim to assess behaviours and not a single biological parameter. Indeed, EBR does not focus on organ damage alone, but recovery from disability and participation, placing the person at the center of the activity.

In this regard, we have aimed to consider those branches of medicine, such as Narrative-Based Medicine (NBM), Psycho-Neuro-Immuno-Endocrinology (PNEI) and the connection with Empathy, which put into practice the centrality of the patient and have a positive correlation with EBM.

Today more than ever, the term "to treat" refers to not only the implementation of the best therapeutic practices, but also returning to its original meaning. It must also involve caring for and accommodating the person who is experiencing the painful condition [6].

Narrative-Based Medicine (NBM) is part of this context. In fact, it is the form of medicine that makes reference to not only the patient's experience, but also the experience of the healthcare professional, and above all the "narrative" relationship that develops between them. What the founder of Narrative-Based Medicine, Rita Char on, has called the "marriage" between Evidence and Narrative has proved even more effective [7]-[9]. In recent years, several studies have been conducted, and many trials are still ongoing. The results obtained highlight how integrating EBM with NBM can offer, as well as an important ethical dimension, substantial practical advantages, such as a better "therapeutic alliance", more effective diagnostic results, stronger adhesion to the treatment plan and increased confidence in the care offered [10]. Also, in the field of rehabilitation, in which it is difficult to manage the problems of patients with a single procedure, a model based on EBM and NBM can represent a powerful tool to achieve results closer to realistic concrete expectations, giving space to the world of the patients, reducing conflict and improving the quality of the work of operators, thus enabling more effective care pathways.

Another new medical discipline that can be added is Psycho-Neuro-Endocrine-Immunology. PNEI became a clinically recognised science at the beginning of this century, thanks to intensive research and experimentation, which has established a connection between the brain, stress and immunity [11] [12]. The PNEI model interprets health and illness through a truly unified vision of the individual in their psychological, biological and environmental identity. For the health care professionals, following the PNEI model involves constant awareness that organic disorders are always in some way related to emotional issues, and vice versa. The three major systems of biological regulation, the immune, endocrine and neurological systems, influence each other, share a dialogue, and use molecules that may, at the same time, act as neurotransmitters, hormones and cytokines [13]-[15]. In rehabilitation, following/implement the PNEI model will mean providing patients, especially the patients with disease and/or chronic pain, with a different approach, through stress management, physical activity and proper nutrition, thus positively affecting their lifestyle.

With regard to the connection with empathy, it has been established that rehabilitative practice has always 
given great importance to the therapist-patient relationship. The therapeutic relationship that develops between the two parties is commonly considered to be essential to the outcome of the rehabilitation process. A good therapeutic relationship requires the establishment of a high level of empathy, and the ability of the operator to see the situation through the patient's eyes, to enter into their thoughts and their meanings, even if they are different from our own, and get in touch with what the patient feels and see things from their perspective. Also in this case, as with narrative medicine and PNEI, several studies have been conducted, and the results obtained demonstrate not only an advantage for the patient who, quite naturally, prefers to work with a health care professional who is not only well trained, but also empathetic and willing to listen and understand their state of mind, but also greater satisfaction for the operator, resulting in a more successful outcome of the disease. Being empathetic has been correlated with better therapeutic results (outcomes) and less medico-legal litigation [16] [17].

All of this proposes the inclusion in rehabilitation of therapeutic models that are moving towards an integrated management of the patient, along with better patient compliance, which could result in a reduction of costs.

This is especially true, as economic policy, with limited healthcare costs, must increasingly provide for an aging population. The aging demography is one of the most significant phenomena in the 21 st century, and entails an increase in chronic and degenerative diseases. Thus, to maintain the current level of "health and wellbeing", it is necessary to identify economically compatible and sustainable alternatives in the near future.

Figure 1 clearly illustrates the evolution of health care. The 1970s saw the first consideration of efficiency, followed by effectiveness, leading to, in the present day, a discussion of integrated governance, which includes clinical aspects, finance, management, research, the safety of patients and workers, and information and technology [18].

The European framework of health spending is significantly burdened by the management of chronic pain, which affects 1 out of 5 persons [19]. On average, these people can live with chronic pain for a period of time that can last for up to 7 years [20]. The health systems of the various states must pay a total of $€ 3300$ bn [21]. About $90 \%$ of this figure is made up of indirect costs, such as lost productivity, social security and the payment of public subsidies. About $1 / 3$ of survey participants state that chronic pain has a negative impact on household income, with an average decrease of $31 \%$ in Europe, leading to a series of additional tensions which exacerbate the patient's condition. Conventional therapies prove effective for less than half of the participants. The most frequently used treatments against chronic pain are NSAIDs, antineuropathic medication and opioids, despite progress made in treatment [19].

In this regard, it is clear how the health care is moving towards the centrality of the patient. Indeed, the World Health Organization (WHO) has indicated among the priority objectives of "Health 2020" (Figure 2) the provision of facilities and services that will encourage citizens/patients to make use of their own resources and be an active part of the system, promote improved information and knowledge, give space to the patient's voice and build a health system that is oriented towards the patient and limiting healthcare costs, and at the European level, the concept of patient oriented healthcare is included in the more general principle of empowerment [22] [23].

The combination of the various therapeutic models described could represent a reduction in health care costs, moving from a system that treats pathologies to a set of integrated interventions that take care of the actual needs of people, and could therefore be productive in a correct allocation of resources.

In conclusion, it will take time, organizational skills and specific experiments to radically change the understanding of health care and rehabilitation, and limit the gap between research and clinical experience [5], through the development of a framework that combines various therapeutic models (Figure 3), but this repre

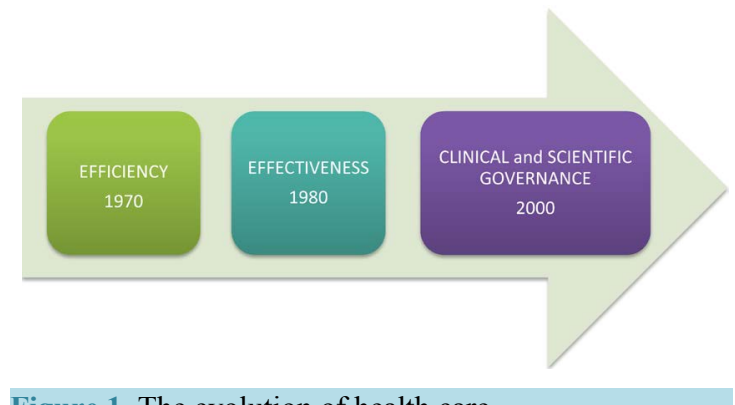

Figure 1. The evolution of health care. 


\section{“Health 2020"}

The creation of structures and services capable of:

- Encouraging the citizen/patient to use their own resources

- Being an active part of the system

- Promoting improved information and awareness

-Giving space to the patient's voice

- Creating a patient centred health system

Figure 2. The priority objectives of "Health 2020 ".

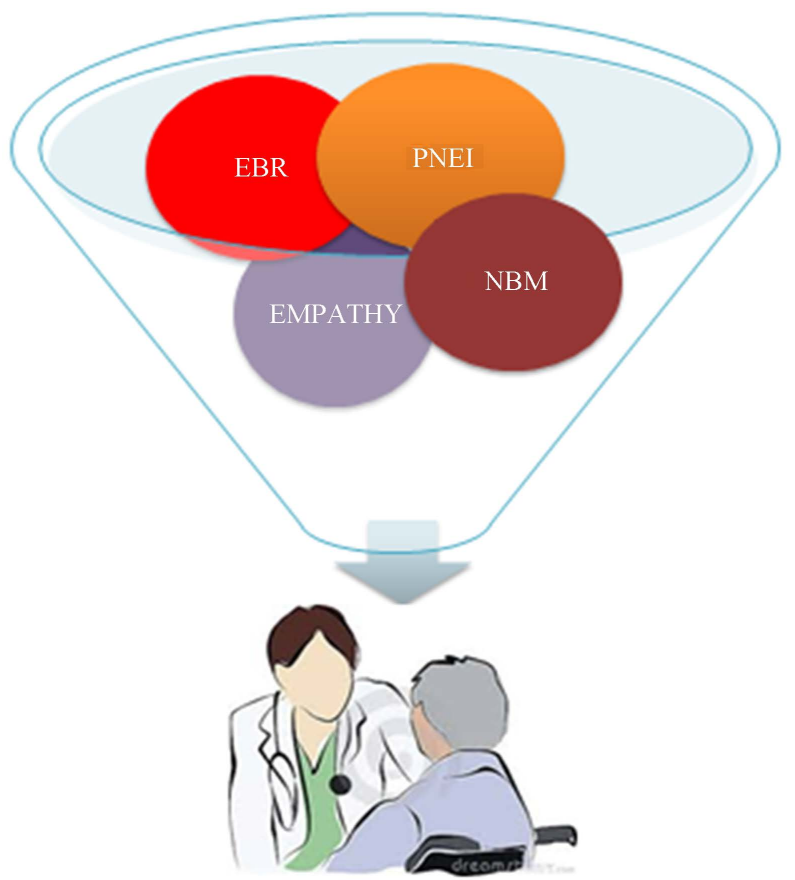

Figure 3. Development of a framework that combines various therapeutic models.

sents the ideal path towards a better response for the patient and an improvement in well-being and healthcare, with a higher healthy life expectancy and better use of reduced economic resources.

\section{Acknowledgements}

The authors would like to thank Dr. Liam Boyle for translating and editing this paper.

\section{References}

[1] Christensen, A.J. (2004) Patient Adherence to Medical Treatment Regimens. Yale University Press, London.

[2] Maher, C.G., Moseley, A.M., et al. (2008) A Description of the Trials, Reviews, and Practice Guide-Lines Indexed in the PEDro Database. Physical Therapy, 88, 1068-1077. http://dx.doi.org/10.2522/ptj.20080002

[3] Herbert, R.D., Maher, C.G., et al. (2001) Effective Physiotherapy. BMJ, 323, 788-790. http://dx.doi.org/10.1136/bmj.323.7316.788

[4] Sackett, D., Strauss, S., et al. (2000) Evidence Based Medicine-How to Practice and Teach EBM. 2nd Edition, Churchill Livingstone, London, 5-7.

[5] Dawes, M., et al. (2005) Sicily Statement on Evidence-Based Practice. BMC Medical Education, 5, 1.

[6] Ginestra, A., Venere, A. and Vignera, R. (2008) Elementi di comunicazione per le professioni sanitarie. Franco Angeli, 
Milano.

[7] Decety, J. and Lamm, C. (2006) Human Empathy through the Lens of Social Neuroscience. Scientific World Journal, 6, 1146-1163. http://dx.doi.org/10.1100/tsw.2006.221

[8] Greenhalgh, T. (1999) Narrative Based Medicine: Narrative Based Medicine in an Evidence Based World. BMJ, 318, 323-325. http://dx.doi.org/10.1136/bmj.318.7179.323

[9] Charon, R. (2001) Narrative Medicine: A Model for Empathy, Reflection, Profession and Trust. The Journal of the American Medical Association, 286, 1897-1902. http://dx.doi.org/10.1001/jama.286.15.1897

[10] Silva, S.A., Charon, R. and Wyer, P.C. (2011) The Marriage of Evidence and Narrative: Scientific Nurturance within Clinical Practice. Journal of Evaluation in Clinical Practice, 17, 585-593. http://dx.doi.org/10.1111/j.1365-2753.2010.01551.x

[11] Charon, R. and Wyer, P. (2008) Narrative Evidence Based Medicine. The Lancet, 371, 296-297. http://dx.doi.org/10.1016/S0140-6736(08)60156-7

[12] Charon, R. (2001) Narrative Medicine: Form, Function, and Ethics. Annals of Internal Medicine, 134, 83-87. http://dx.doi.org/10.7326/0003-4819-134-1-200101020-00024

[13] Besedovsky, H. and Sorkin, E. (1977) Network of Immune-Neuroendocrine Interactions. Clinical Experimental Immunology, 27, 1-12.

[14] Weigent, D.A. and Blalock, J.E. (1987) Interactions between the Neuroendocrine and Immune Systems: Common Hormones and Receptors. Immunological Reviews, 100, 79-108. http://dx.doi.org/10.1111/j.1600-065X.1987.tb00528.x

[15] Dantzer, R. (2005) Somatization: A Psychoneuroimmune Perspective. Psychoneuroendocrinology, 30, 947-952. http://dx.doi.org/10.1016/j.psyneuen.2005.03.011

[16] Hojat, M., Gonnella, J.S., Mangione, S., Nasca, T.J., Veloski, J.J., Erdmann, J., Callahan, C.A. and Magee, M. (2002) Physician Empathy: Definition, Components, Measurement, and Relationship to Gender and Specialty. American Journal of Psychiatry, 159, 1563-1569. http://dx.doi.org/10.1176/appi.ajp.159.9.1563

[17] Libba, R.M. (2007) Empathy and Empathic Communication: Nursing Student Perceptions of Program Effectiveness, Academic Experiences, and Competence. Dissertation, Auburn University, School of Nursing, Auburn.

[18] Muir Graj, J.A. (1997) Evidence-Based Healthcare. Churchill Livingstone, London.

[19] British Pain Society (2012) Pain in Europe: A Report.

[20] Painful Truth Survey. IML Research.

[21] Galluzi, K. (2005) Management of Neuropathic Pain. Journal of American Osteopathic Association, 105, s12-s19.

[22] Jakab, Z. (2012) Patient Empowerment in the European Region-A Call for Joint Action. Proceedings of the First European Conference on Patient Empowerment, Copenhagen, 11-12 April 2012, 11.

[23] The Lancet (2012) Patient Empowerment-Who Empowers Whom? The Lancet, 380, 650. http://dx.doi.org/10.1016/S0140-6736(12)60699-0 
Scientific Research Publishing (SCIRP) is one of the largest Open Access journal publishers. It is currently publishing more than 200 open access, online, peer-reviewed journals covering a wide range of academic disciplines. SCIRP serves the worldwide academic communities and contributes to the progress and application of science with its publication.

Other selected journals from SCIRP are listed as below. Submit your manuscript to us via either submit@scirp.org or Online Submission Portal.
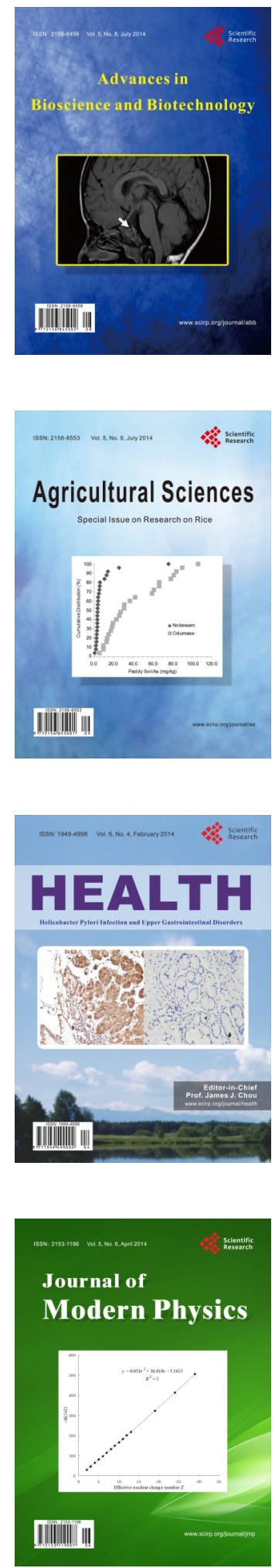
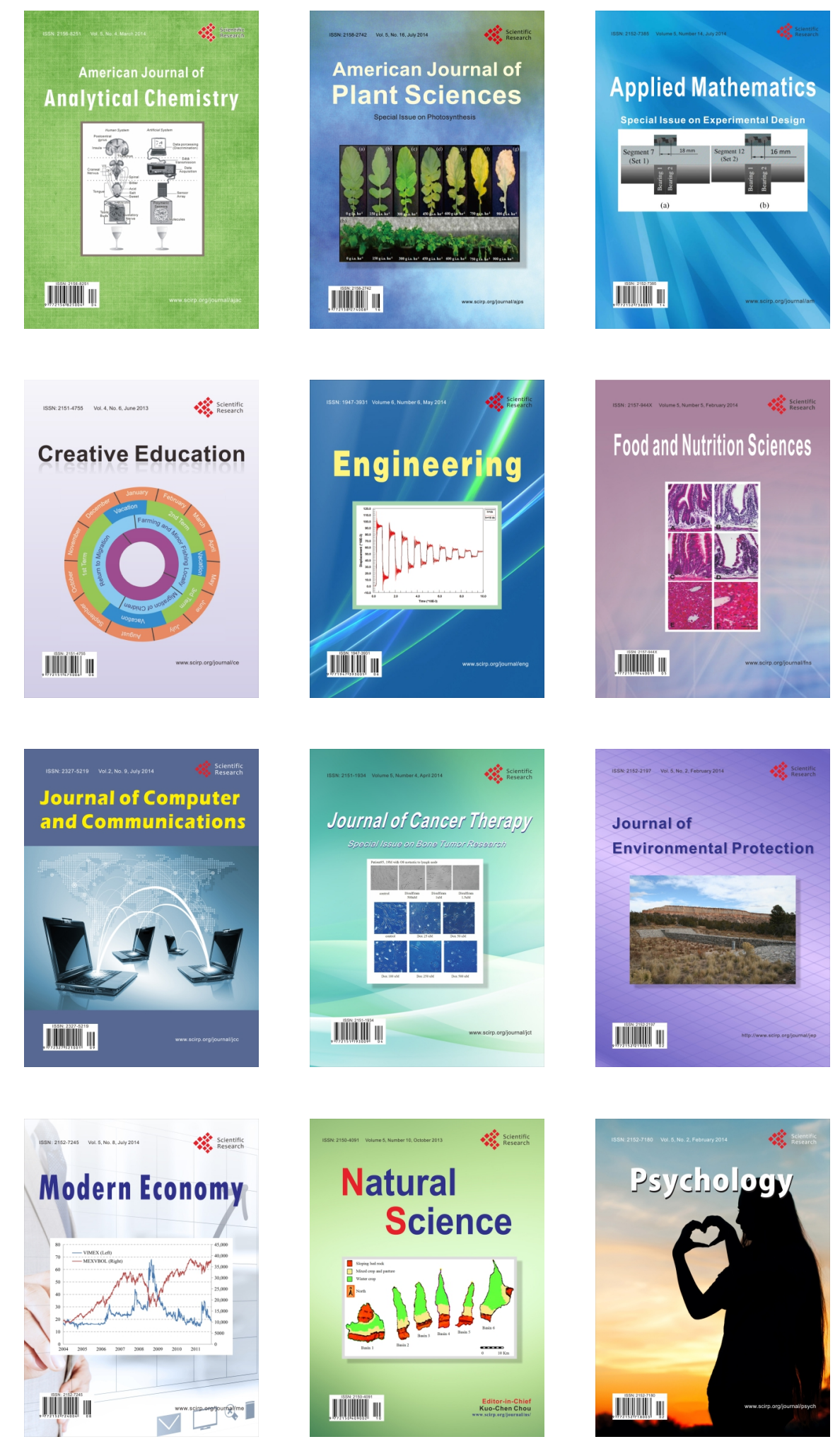